\title{
Implications of Industrialized Building System on Labor Demand and Cost
}

\author{
Yong Chen-Chen ${ }^{1 *}$, Rusmawati Said ${ }^{2}$, Candy Gan Chin Yee $^{3}$
}

${ }^{1,3}$ Faculty of Economics \& Administration, University of Malaya, 50603 Kuala Lumpur, MALAYSIA

${ }^{2}$ Faculty of Economics and Management, Universiti Putra Malaysia, 43300 Serdang, Selangor, MALAYSIA

${ }^{*}$ Corresponding Contact:

Email: ccyong@um.edu.my

\begin{abstract}
High dependence on foreign workers in the construction industry has been long known to be one of the contributing factors of labor demand issue. To address this problem, the implementation of new technology innovations, such as the Industrialized Building System (IBS) is suggested. The purpose of this research paper is to identify the implication of IBS on the labor requirement of the construction industry. In this paper, the authors used the survey-questionnaire method. The research involved data from the surveys completed by the contractors registered with the CIDB. Data Envelopment Analysis (DEA) has been applied, and the reliability of the DEA result has also been proved. The result obtained from the Data Envelopment Analysis (DEA), indicates that IBS contractors are still required to hire an unskilled worker to undergo the new technology transition. However, when the adoption rate of IBS gets higher, the issue of substantial influx and dependency on a foreign worker in the construction industry can be resolved gradually. Although the investment cost is high during the initial stage, IBS can help to reduce the construction cost in the long-term.
\end{abstract}

Key words:

IBS, Labor, Construction Industry, DEA

$12 / 27 / 2018$

Source of Support: None, NoConflict of Interest: Declared

This article is licensed under a Creative Commons Attribution-NonCommercial 4.0 International License.

Attribution-NonCommercial (CC BY-NC) license lets others remix, tweak, and build upon work non-commercially,

and although the new works must also acknowledge \& be non-commercial.

\section{INTRODUCTION}

Construction industry makes up a significant part of the Malaysia economy. There are numerous industries inter-connected to it, such as basic metal products and electrical machinery. The Construction industry is essential for the country's revenue contribution, capital formation, and employment. As a result, this industry helps to bolster the gross domestic product (GDP) of the country. Likewise, the Construction sector also contributes to the national economic development significantly by generating more employment opportunities for both skilled and unskilled labor. Therefore, it subsequently boosts the GDP and socio-economic development of human life in the country. 
Through some re-engineering strategies in the $11^{\text {th }}$ Malaysia Plan, the Government has strived hard to improve and transform the construction industry. For instance, to drive productivity in the construction industry, the knowledge content of construction has to be enhanced. Similarly, sustainable practices have to be fostered to increase the internationalism of construction firms (EPU, 2015). By 2017, the growth of construction industry is expected to be RM170 billion or 8 percent due to the undertaking of various mega infrastructure projects in Malaysia, such as Refinery and Petrochemical Integrated Development project in Johor as well as Mass Rapid Transit Two in Klang Valley. These projects are expected to boost demand in the sector and allow the construction industry to grow 7.4 percent with RM166.4 billion.

Economic efficiency will be improved along with the growth in the construction industry. More locally produced materials and human capital consumed in building and maintaining the constructions and infrastructures, will thus encourage more local employment. The Malaysian construction industry in the year 1957 was characterized to be highly labor intensive with low technology adoption rate. As of now, the industry is offering millions of job opportunities to unskilled, semi-skilled and skilled people. Since 2000, it has been seen that the employment opportunity in the construction sector has been increasing steadily at a compounded growth of 3.5 percent (see Figure 1).

Figure 1: Employment in Construction Sector

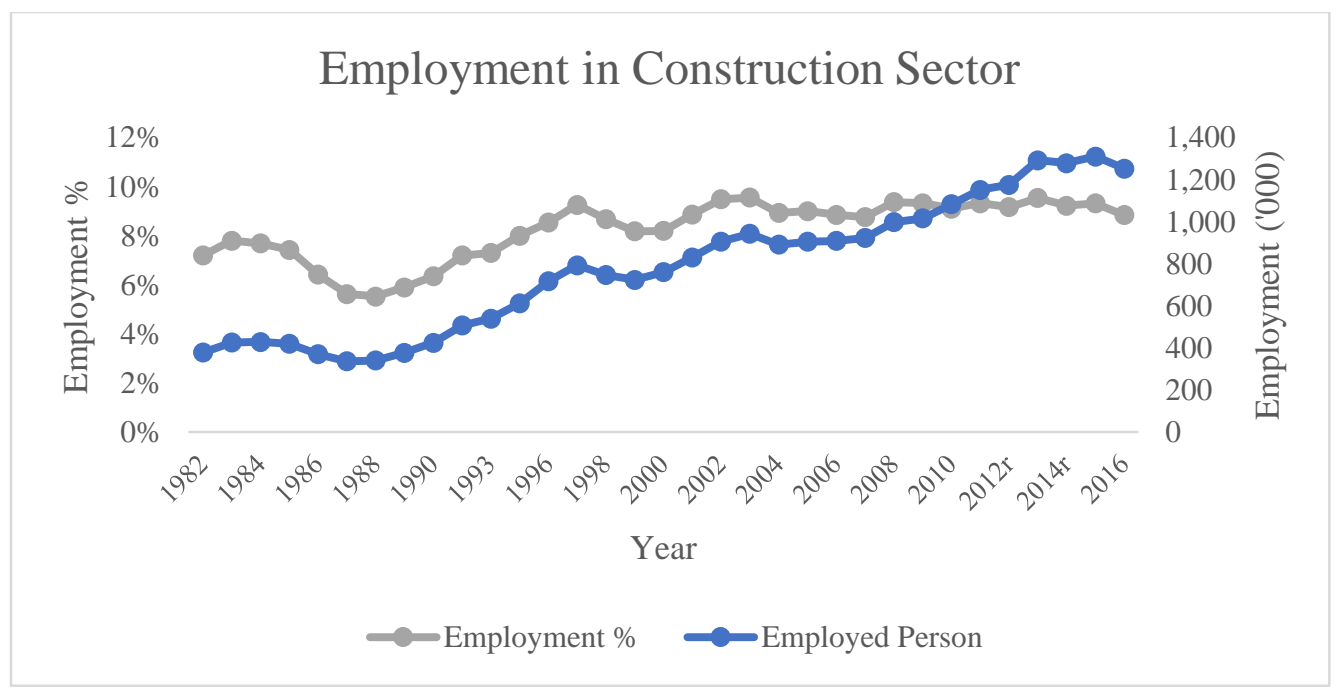

Source: Department of Statistics Malaysia

The statistics from $2011^{\mathrm{r}}$ to $2014^{\mathrm{r}}$ were updated based on the population estimates of the respective years

To propel Malaysia into prosperity and catapult it towards a high-income nation by 2020, the construction industry plays an important role. Currently, the government authorities have implemented few approaches to help build better and resilient construction industry. Examples of those efforts are such as CITP, $10^{\text {th }}$ Malaysian Plan and Economic Transformation Programme (ETP). All these ways aim to transform the construction industry and advocates more local workers' involvement. As the country is moving towards the transformation, there is a need to be concerned about the current labor management in the industry, especially the distribution of local and foreign workers. The labor shortage is 
very crucial in the industry as it will affect the government project plan. The planning of future human capital requirement is required to ensure the government project is successful.

This study was conducted to ensure the significance of today construction labor composition and the criteria for construction labor recruitment and selection, especially on the level of foreign worker dependency. This study will also provide useful insight into the employment and skill requirement in each building types of the construction industry. As a result, this study will be meaningful for policy makers and authorities, like the Malaysian Government, Human Resource Department, and others to plan and take action on reducing the foreign worker dependency in Malaysia. At the same time, it also aids to decrease the unemployment rate in Malaysia by reducing the employment of foreign labors.

\section{OVERVIEW OF THE LANDSCAPE OF CONSTRUCTION INDUSTRY IN MALAYSIA}

The heavy inflow of foreign workers has always been associated with the labor demand in the domestic industry. The bad perception of 4D (dirty, dangerous, difficult and demanding) has been ingrained among the Malaysian for a long time, especially among the youngsters, leading to low participation of local workers in the industry. Therefore, the construction industry is facing a critical labor shortage in sustaining the huge construction demand and development in Malaysia (Zaki et al., 2012; Hamid et al., 2013). A consequence of this phenomenon is the high demand for foreign workers to replace the vacancies created.

The low wage structure in the Malaysian construction industry has been threatening the local workers to compete with the economic foreign workers from neighboring countries, such as Indonesia, Thailand, Philippines, Sri Lanka, India and Bangladesh (Navamukundan, 2002). Labor cost has been long known to be comprised of 20 to 50 percent of the overall building cost (Alinaitwe et al., 2006; Jarkas and Bitar, 2011; Jarkas and Younes, 2014). Thus, to maintain the construction cost, the primary variable needs to be adjusted. Therefore, many contractors hesitate to increase wages and provide a better working environment to attract and retain local workers as it will increase the burden on their expenses.

Industrial Building Systems (IBS) is an innovation which has been mooted since the sixties. Generally, the advantages of IBS implementation can be categorized into five groups as follows, (1) reduce the construction time, (2) reduce the total cost, (3) reduce the dependency of foreign worker, (4) improve the quality of buildings, and (5) promote safer and cleaner factory working environment(Oliewy et al., 2009). It is also known as pre-fabricated construction, endorsing a different way of construction. Conventional construction methods conduct every single step at the construction site, thus leading to longer construction time. However, IBS technology allows the prefabrication process of the construction elements at the factory and the foundation work at the site to be carried out simultaneously. IBS method will be far more efficient and will, therefore, push towards a faster process.

CIDB proposed in the CIMP 2006-2015 to move towards a knowledge-based industry by adopting innovation methods. More skilled workers are still needed in IBS due to the highly mechanized in-situ processes, i.e., slip-forms, post-tensioning and tunnel shutters. Consequently, this can reduce our reliance on mostly foreign unskilled labor. In addition to that, the implementation of IBS, promises lower onsite worker requirements due to its simplified construction method and elimination of conventional timber formwork. Nevertheless, the current construction market in Malaysia suffers from the lack of skilled workers and professional (Zaki et al., 2012). The skilled labors with specific skills are 
critically required in future construction market to meet the construction need. Moreover, a limited literature review has been conducted to identify the human capital demand and the implication of IBS technology on the management of the construction industry.

High precision and accuracy are needed for IBS implementation which will consequently create more job opportunities for skilled workers. Most of the foreign workers are involved in the construction industry as unskilled workers due to their low education level. As a result, the adoption of IBS technology is expected to transform the construction industry by substituting the tasks conducted by these unskilled workers. The planning of future human capital requirement is required to ensure the government project is successful.

The labor costs can be controlled as most of the projects in the country were employed through subcontractors (Arif et al., 2015). However, the labor requirement needs to be estimated for the labor cost budgeting. At the same time, the labor shortage is a common issue happening in the construction industry. The local workers are unwilling to join the industry, creating an opportunity for the inflow of foreign workers. Therefore, the IBS technology has identified as one of the resolutions to reduce the high dependency of the foreign worker. However, there is limited literature review conducted to recognize the human capital demand and the implication of IBS technology on its management. The impact of the IBS technology on the labor requirement is also very scarce. Hence, this research report plans to fill the gap by exploring and comparing the manpower requirement by different building types. It aims to (1) determine the employment in the industry; (2) investigate the foreign worker dependency level, and (3) examine manpower requirement by work categories.

\section{Methodology}

Labor cost is one of the construction costs which can be estimated based on the necessity of the industry. Their impact on construction cost is so significant that we need to assess the actual labor demand. Besides, the adoption of the innovation, IBS would help to resolve the issue of heavy influx of the foreign workers. Hence, it is necessary to check on the result whether to encourage contractors to adopt such innovation.

\section{Research Data and Collection Method}

A viable quantitative approach was implemented to gather data and information regarding to the current labor demand in the construction industry in Malaysia. Given, a large number of contractors, a paper survey-questionnaire method was designed to collect the data from each construction firm as firm-level data is not available or accessible to the public. The survey data has been collected as a primary source of information to serve as a representative sample and to reflect the "reality." Therefore, the data obtained is more trustworthy and credible.

The data were obtained from the survey done by CIDB under the title of "Human Resources Management in Construction Industry in Malaysia." This survey was designed and administered to collect some random samples from the construction firms in the industry. A total of 1,052 construction firms participated in the survey in the year 2016. The descriptive statistics have been used to interpret the general characteristics of the data. The data is then divided into groups to measure and compare the performance of Malaysian construction sector across different building types. The building types that we gathered are conventional, IBS, infrastructure, and others, like the power plant, marine structure and telecommunication. 


\section{Data Cleaning}

To produce an accurate outcome, data cleansing is a necessary attempt before conducting the analysis. It is a measure to recognize and rectify the error and inconsistency in the data set. This step is crucial to ensure the data is consistent, complete, accurate and homogenous. At the same time, data quality also can be assured, which can lead to a right insight for the decision being made (Patel, 2012; Devi and Kalia, 2015)

Missing Data: One of the common issues in research is having missing data. There are a few factors which can lead to the missing data occurrence in survey-questionnaire. One of the examples is nonresponse. Respondents could be ignoring or overlooking the questions where no information is provided. Other circumstances are such as the inquiry is irrelevant to the respondents and attrition missing (Kang, 2013; Cheema, 2014). There are many ways which can be used to handle such missing data, like deletion methods, single imputation methods and model-based methods.

As the name suggests, deletion methods eliminate the data which contains missing data. A listwise deletion method is a simple approach where only cases with available data on each variable will be analyzed. Nonetheless, this will lead to lower statistical power due to the smaller sample size. Pairwise deletion is another method to investigate all the cases in which the variable of interest is present. More cases can be kept for analysis as compared to likewise deletion, but a comparison cannot be done as the sample can be different at each time.

In this paper, listwise deletion or also known as complete case analysis has been employed. After scrutinizing the data, there are only seven firms affected, which is $0.7 \%$ out from the entire samples. The affected sample count is not significant as compared to the whole population. Four samples, S31, S52, S79 and S635 are removed due to the unavailability of labor figure. Samples S702 and S703 are discarded for their missing registration grade and project value. Without the project value, we cannot estimate the required worker count. Last but not least, sample S688 has been pulled out of the analysis for the reason of missing project period.

Outlier Handling: Outlier usually refers to samples of data which are significantly different from the rest of the data. The data distribution can be skewed by extremities which will influence the outcome and decision making. Thus, the process of identification and handling outliers is vital before the statistical analysis (Bakker and Wicherts, 2014); (Liao et al., 2016); (Rousseeuw and Van Zomeren, 1990).

Absolute of the standard score is one of the easiest and favorable approaches used to detect the outliers. The value of the observation will be normalized or standardized. The standard score is also known as Z-value or standardized variables. The calculation of Z-value is shown as $z=\frac{x-\mu}{\sigma}$ where $\mu$ and $\sigma$ refer to the mean and standard deviation of the population.

It shows the distance of the sample against the population mean. The sample with positive standard score implies that its value is above the mean, and vice versa. Since the population mean is not possible to obtain, the mean and standard deviation has been estimated by using the random samples. The threshold value for a standard score of 3 has been predetermined. Other practices to identify the outliers are such as median absolute deviation statistic (MAD) and the interquartile range (IQR) (Berkane \& Bentler, 1988; Barnett et al., 1995; Cook, 1986; 
Gnanadesikan, 1997; Jarrell, 1991; Liao et al., 2016). (Berkane and Bentler, 1988);(Barnett et al., 1995); (Cook, 1986); (Gnanadesikan, 2011); (Jarrell, 1991);(Liao et al., 2016).

Standard score approach has been adopted in this paper to detect the anomalous data. There are four samples categorized as outliers. The project value for the samples S29, S35, S123 and S707 has been standardized to 8.30, 27.86, 12.07 and 5.44 respectively. Their Z-values are greater than 3. A graph has been plotted by using the data project value versus project period to identify outliers. Figure 2 shows that four samples data are plotted far from the remainders.

Figure 2: Scatterplot of project value and project period before removing outliers

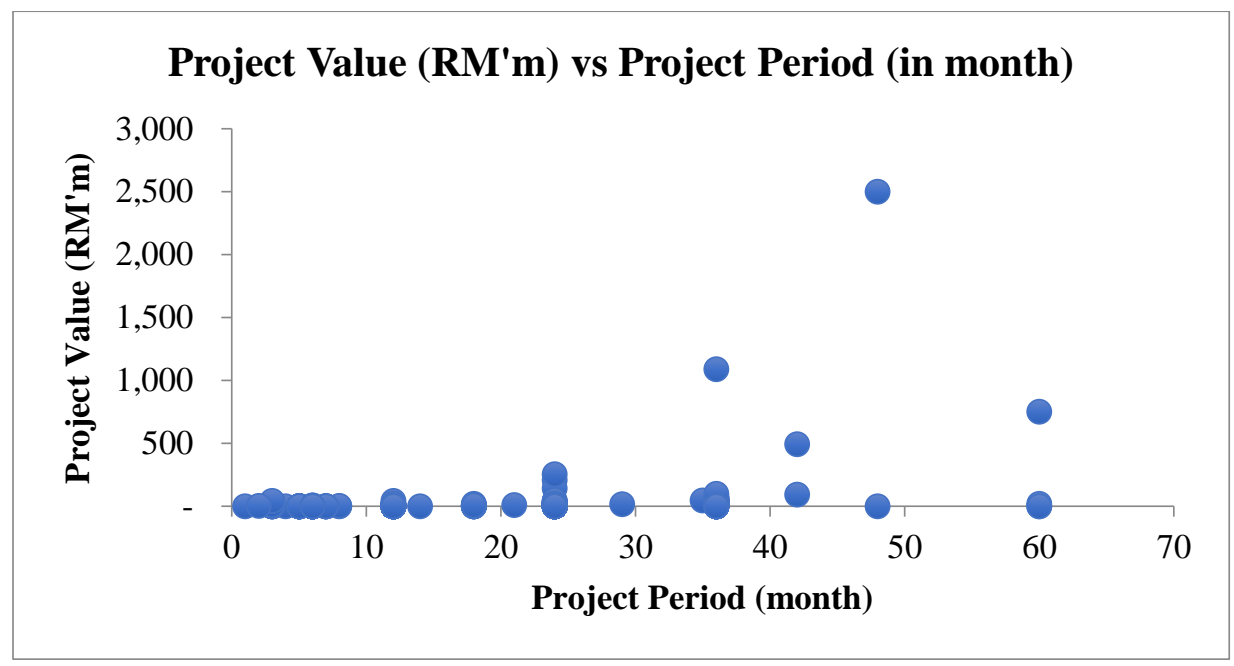

Following by the step of outlier detection, the removal of an outlier is also vital in data cleaning or cleansing process (Adikaram et al., 2014); (Beckman and Cook, 1983); (Molinari, 2010); (Qin et al., 2009). It is crucial to obtain a data set with no outliers or as few as possible (Adikaram et al., 2014). Therefore, the four outlier firms will be removed from the analysis and the graph is plotted after the outlier removal (see Figure 3).

Figure 3: Scatterplot of project value and project period after removing outliers

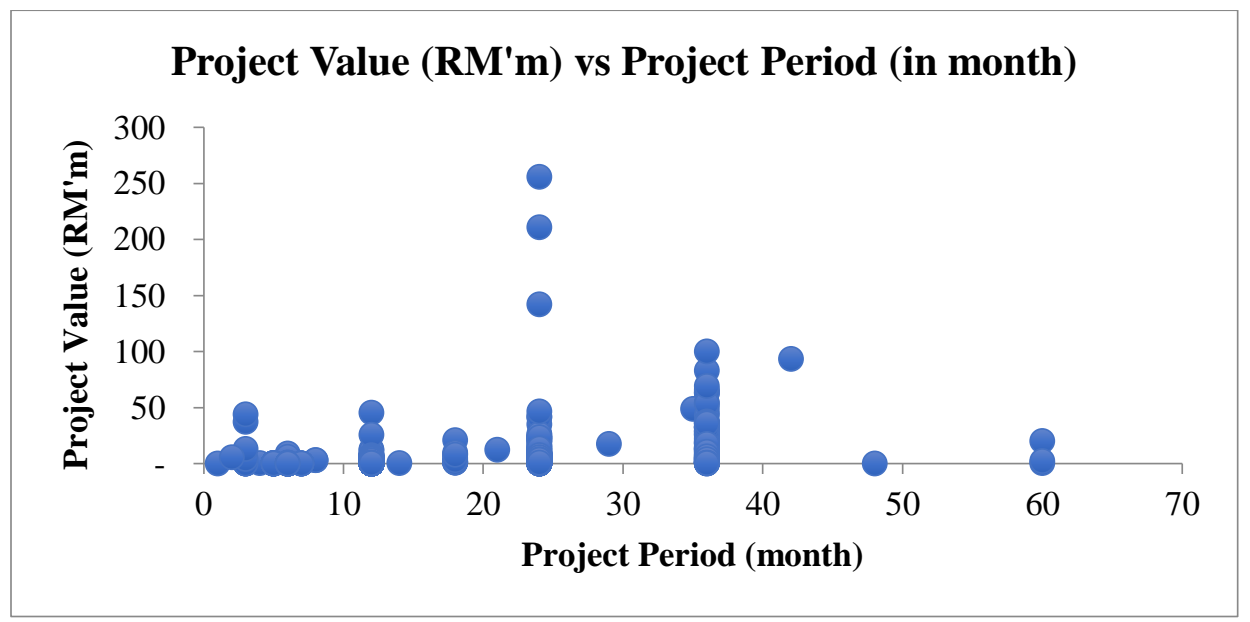


Data Auditing: Data auditing is a process of data scrutiny and verification to remove the anomalies from the data set (Devi and Kalia, 2015). This data checking step is necessary to ensure the data's integrity and ability to support the definitions or assumptions in the analysis. For instances, CIDB has set up a maximum project value which is allowed by each registration grade. From Table 1, all the firms with registration grade from G1 to G7 which are found to exceed their entitlement have been removed. There is a total of 18 contractors to be removed from the subsequent analysis. After few steps of data cleaning above, there is a total of 1,030 contractors remaining for the following analysis.

Table 1: Project Values by Registration Grade

\begin{tabular}{|c|c|c|c|c|}
\hline $\begin{array}{c}\text { Registration } \\
\text { Grade }\end{array}$ & $\begin{array}{c}\text { Number of } \\
\text { Contractor }\end{array}$ & $\begin{array}{c}\text { Min Project } \\
\text { Value }\end{array}$ & $\begin{array}{c}\text { Max Project } \\
\text { Value }\end{array}$ & $\begin{array}{c}\text { Max Value Allowed } \\
\text { (RM million) }\end{array}$ \\
\hline G1 & 184 & 0.01 & 0.20 & 0.20 \\
\hline G2 & 148 & 0.02 & 0.47 & 0.50 \\
\hline G3 & 135 & 0.02 & 0.96 & 1.00 \\
\hline G4 & 85 & 0.06 & 2.74 & 3.00 \\
\hline G5 & 100 & 0.06 & 4.80 & 5.00 \\
\hline G6 & 144 & 0.02 & 10.00 & 10.00 \\
\hline G7 & 233 & 0.06 & 255.84 & No limit \\
\hline Foreign & 1 & 45.29 & 45.29 & \\
\hline Grand Total & 1,030 & 0.01 & 255.84 & \\
\hline
\end{tabular}

\section{Data Envelopment Analysis (DEA)}

The efficiency of a company or organization can be examined when all the resources have been used up optimally to produce the maximum output. Efficiency can explain the relationship of the outputs which are produced from the inputs by an organization. DEA is the best approach to be used to identify the organization's efficiency. In the interest of labor demand identification, the labor count will be tested. Breakdown of the labor by permanent and contract will be diagnosed to understand the requirement of the local and foreign worker. Permanent and contract workers are used as proxies for local and foreign workers respectively due to the nature of their working periods.

DEA models with VRS condition will be applied on the human capital subject to the cost minimization. Output-oriented DEA has been carried out to identify the potential cost when the firm is in the best practice frontier. The translog cost function outlines and illustrates the number of inputs needed to produce a set level of output, to achieve optimum cost (Greene, 2003). The basic translog cost function is shown as: -

$\ln T C=\beta_{0}+\beta_{y} \ln y+\frac{1}{2} \beta_{y} y(\ln y)^{2}+\beta \sum_{i} \beta_{i} \ln w_{i}+\frac{1}{2} \sum_{i} \sum_{j} \alpha_{i j} \ln w_{i} \ln w_{j}+$

$\beta_{i y} \sum_{i} \ln w_{i} \ln y$

where $T C$ is the total cost, $w_{i}$ shows the price of input $i$, and $y$ is the output.

The DEA function is hypothesized with the properties that (1) the production probability set is convex, and (2) the input and output are readily available. Supposed there are $m$ output vectors of the firm $j y_{j}=\left(y_{1 j}, y_{2 j}, \ldots, y_{m j}\right)$ with $n$ input vector $x_{j}=\left(x_{1 j}, x_{2 j}, \ldots, x_{n j}\right)$, the production possibility established under the VRS assumption is 
$T^{v}=\left\{(x, y): x \geq \sum_{j=1}^{N} \lambda_{j} x^{j} ; y \leq \sum_{j=1}^{N} \lambda_{j} y^{j} ; \sum_{j=1}^{N} \lambda_{j}=1 ; \lambda_{j} \geq 0(j=1,2, \ldots, N)\right.$

For any of the output vectors, there is some requirement on the input sets, as follows.

$V(y)=\left\{(x): x \geq \sum_{j=1}^{N} \lambda_{j} x^{j} ; y \leq \sum_{j=1}^{N} \lambda_{j} y^{j} ; \sum_{j=1}^{N} \lambda_{j} \geq 0(j=1,2, \ldots, N)\right.$.

Under the VRS assumption, the minimum cost for a target output $y^{0}$ with a given level of input price vector $p^{0}$ is $C^{*}=\min p^{0}{ }^{\prime} x: x \in V\left(y^{0}\right)$. The cost minimization can be achieved by using the DEA method:

$\operatorname{Min} \sum_{i=1}^{n} p_{i}^{0} x_{i}$

s.t. $\quad \sum_{i}^{n} \lambda_{j} x_{i j} \leq x_{i} \quad$ where $i=1,2, \ldots, n$;

$\sum_{i=1}^{n} \lambda_{j} y_{r j} \geq y_{r 0} \quad$ where $r=1,2, \ldots, m$;

$\sum_{i=1}^{n} \lambda_{j}=1$

$\lambda_{j} \geq 0 \quad$ where $j=1,2, \ldots, N$.

The optimal solution of the cost minimization objective is expected to produce cost minimizing input vector $x^{0}=\left(x_{1}^{*}, x_{2}^{*}, \ldots, x_{n}^{*}\right)$ with $C^{*}$ as the minimum. At the optimal solution, it is expected that all the constraints involving inputs are binding, which mean there will not be any input slacks.

The DMU which is identified as efficient in BCC model does not imply the result will be the same in the CCR model. However, in BCC model, the DMU can be considered as efficient in correspondence to the CCR model with the condition that the scale efficiency exists (Ertugrul et al., 2016). Below is the computation of scale efficiency.

$S E=\frac{Q_{C C R}}{Q_{B C C}}$

\section{Reliability Test}

Good quality of data can enable us to find out the key information on the current and potential area of improvement. One of the common methods used to validate the data is Bootstrapping. It is a statistical technique used to increase the total number of samples by duplicating the existing sample data. Reliability of the result can be assured, and biases can be corrected through Bootstrapping (Hanrui and Xun, 2011). Bootstrapping is conducted in Microsoft Excel to generate another random data set of 1,030 samples. 
Both original and bootstrapping data were tested to generate the efficiency score. A simple analysis of variance (ANOVA) was carried out to analyze the differences between these two sets of data. The $p$-value from the ANOVA result shows 0.990 , hence, fail to reject the null hypothesis. Original and bootstrapped data are statistically equal at $95 \%$ confidence level. As a result, the internal consistency of the data has been proved, confirming the reliability of DEA result.

\section{RESULT}

This section will display and show the empirical result by using the Data Envelopment Analysis (DEA) method. Each construction firm which represents every single DMU will be analyzed and compared to check their efficiencies. Not all the construction firm are operating efficiently. Therefore, the DEA method for both input- and output oriented will be applied to check on the labor requirement.

Generally, DEA aims to suggest the room of improvement to each DMU. Input-oriented DEA will be applied to check on the number of the workers which needs to be reduced with the same cost. Output-oriented DEA proposes the potential labor cost to be incurred if the construction firm function efficiently. Firstly, the total labor as an overall is tested against the labor cost and vice versa. The analysis is further broken down into the local and foreign worker to measure the dependency of the foreign worker in the industry. Besides, DEA is also tested against the number of workers by their work categories to find out which types of work or skill is facing shortage currently.

\section{Descriptive Analysis of Samples}

$47.2 \%$ and $48.5 \%$ of the samples are constructing conventional and infrastructure-related buildings respectively. These two types of contractors employed more workers compared to other building types. The number of workers who worked in conventional and infrastructure projects is 16,343 (56\%) and 10,041 (35\%) respectively (see Table 2).

Table 2: Total Workers by Building Types

\begin{tabular}{|c|c|c|c|c|c|}
\hline $\begin{array}{c}\text { Building } \\
\text { Type }\end{array}$ & $\begin{array}{c}\text { Total } \\
\text { Worker }\end{array}$ & $\begin{array}{c}\text { Proportion } \\
\text { of Worker }\end{array}$ & $\begin{array}{c}\text { Min } \\
\text { Count }\end{array}$ & $\begin{array}{c}\text { Max } \\
\text { Count }\end{array}$ & $\begin{array}{c}\text { Average Count } \\
\text { per Firm }\end{array}$ \\
\hline Conventional & 16,343 & $56 \%$ & 2 & 373 & 34 \\
\hline IBS & 1,996 & $7 \%$ & 4 & 312 & 77 \\
\hline Infrastructure & 10,041 & $35 \%$ & 1 & 180 & 20 \\
\hline Others & 646 & $2 \%$ & 4 & 349 & 36 \\
\hline Grand Total & 29,026 & $100 \%$ & 1 & 373 & 28 \\
\hline
\end{tabular}

However, the results in Table 2 also shows that IBS building types required the highest average workers for each firm, i.e., 77 workers.

Figure 4 depicts the local and foreign proportion of labor in each building type. The local and foreign proportion in conventional building projects does not have a significant difference. The abundance of the cheap workers, especially from Indonesia has always reported to substitute and fill up the vacancy in the construction industry. However, foreign workers, mostly unskilled or semi-skilled, are expected to reduce via the implementation of IBS. Currently, IBS contractors hire more foreign workers as compared to other building types. This could be because the IBS contractors have not as yet completely transformed into the usage of this innovation. 
Figure 4: Local vs. Foreign Proportion in Each Building Types

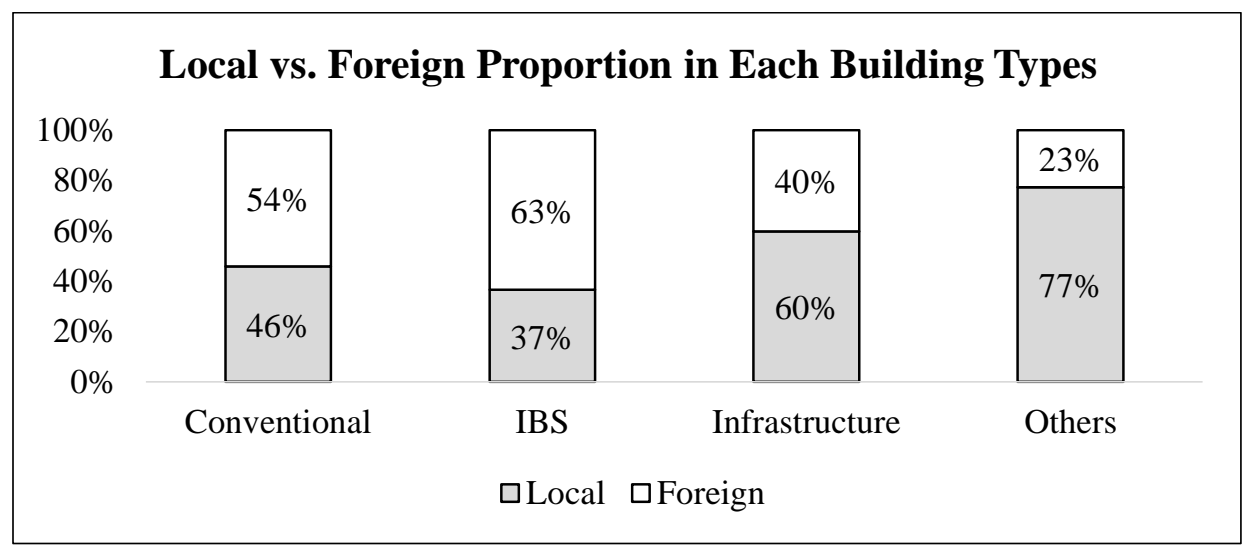

Half of the total workforce work as unskilled workers and only $25 \%$ of the workers are involved as skilled workers. Moreover, the majority of the unskilled and semi-skilled are foreign workers (as in Figure 5). Thus, there is an urgency to encourage the growth of local skilled workers to prevent the overdependence of foreign workers in the construction industry.

Figure 5: Proportion of Total Worker

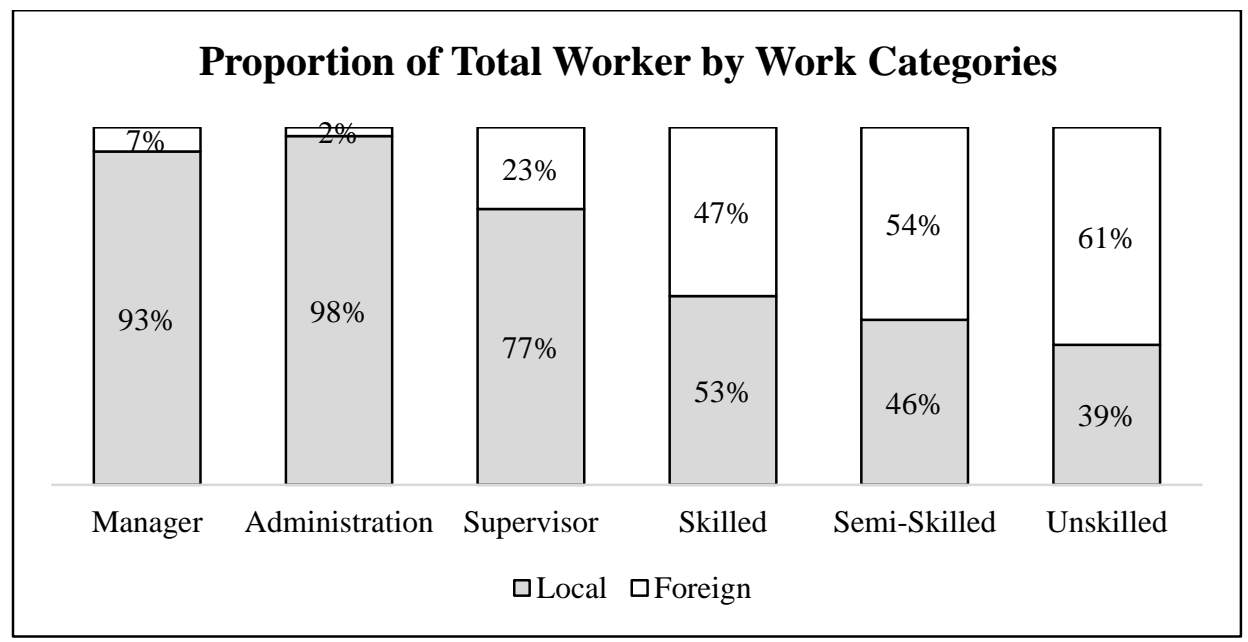

\section{Efficiency of Construction Firm}

If a construction firm is recognized to be inefficient, then they need to either reduce their construction cost or decrease the number of workers. The score for an efficient DMU is equivalent to 1 whereas the score for an inefficient DMU is less than 1.

Total Labor Required: Table 3 represents the Mean of Slack Value for Total Workers. It is seen that IBS will incur higher labor cost, which is RM 326 thousand more. This could be due to the specialization and high skill which is needed in operation. At the same time, the labor is cost also suggested to increase by RM 36 thousand and RM 15 thousand for conventional and infrastructure respectively. More workers need to be employed to achieve efficiency. Conventional and infrastructure need to hire two more workers. 
Table 3: Mean of Slack Value for Total Workers

\begin{tabular}{|c|c|c|}
\hline Building Types & Total Worker & Labor Cost (RM million) \\
\hline Conventional & 1.539 & 0.036 \\
\hline IBS & 0.000 & 0.326 \\
\hline Infrastructure & 2.072 & 0.015 \\
\hline Others & 0.000 & 0.000 \\
\hline
\end{tabular}

Total Local and Foreign Labor Required: Permanent and contract workers have been used to represent the local and foreign workers. IBS needs to hire more local workers, even though its labor cost adjustment is the highest compared to the rest. It is true that IBS would require more local workers who are deemed to have higher knowledge and skill. The labor cost of IBS is suggested to increase by RM 288 thousand (see Table 4). Both conventional and infrastructure also confirm the previous conclusion, i.e., these two building types need to hire more local and foreign workers. These construction methods still require more workers to cover for the inefficient ones as the efficiency of the human can be varied from time to time. Sometimes, they would need to hire a foreign worker to back up the inadequacy of local worker supply.

Table 4: Mean of Slack Value for Total Local and Foreign Workers

\begin{tabular}{|c|c|c|c|}
\hline Building Types & Local & Foreign & Labor Cost (RM million) \\
\hline Conventional & 2.160 & 0.526 & 0.027 \\
\hline IBS & 0.385 & 0.000 & 0.288 \\
\hline Infrastructure & 0.460 & 3.941 & 0.012 \\
\hline Others & 0.000 & 0.000 & 0.000 \\
\hline
\end{tabular}

Total Labor Required by Work Categories: The study continues to find out the human capital requirement by the types of work to confirm the hypothesis made above, especially for IBS (as in Table 5).

Table 5: Mean of Slack Value for Total Worker by Work Categories in IBS

\begin{tabular}{|c|c|c|c|c|c|c|}
\hline & Manager & Admin & Supervisor & Skilled & Semi-Skilled & Unskilled \\
\hline Local & 0.047 & 0.231 & 0.726 & 2.404 & 0.462 & 2.654 \\
\hline Foreign & 0.038 & 0.000 & 0.462 & 5.231 & 1.577 & 11.385 \\
\hline
\end{tabular}

The demand for unskilled foreign workers is still the most, a requirement of 11 additional workers is suggested. The second highest worker demand is skilled foreign labor, i.e., five extra workers, reflecting the current situation in Malaysia. Most of the local skilled workers are not retained in the industry, which consequently results in the large import of foreign workers into Malaysia (Hamid et al., 2013).

\section{Discussion}

Compared to conventional building types, higher labor cost needs to be incurred for the hiring of workers with high skill in IBS. However, this high labor cost helps to encourage the local workers to join the industry, which can, in turn, solve the overdependence of foreign workers. Currently, our construction workers do not have the skill required for IBS. Likewise, more skilled and unskilled workers are needed in the IBS projects. This could be because our construction development is still at the pre-mature stage. Therefore, the development has to take place progressively. Unskilled workers are still required so that the project will not be halted in between. The industry requires some time for the 
transformation and upgrade. In the long term, the automation process of IBS is expected to cover the high expenses in the initial stage.

\section{Policy Implications}

Few initiatives can be suggested to overcome the shortage of worker issue, particularly skilled worker, in the construction industry. The uptake of the construction firm is much slower than the expectation of the government. There are still a lot of construction firms which are unwilling to adopt the innovation. Besides the high investment cost, the abundance of cheap foreign workers also contributes to the problem.

To reduce the need for foreign worker, practical training programs are suggested to produce more local workers with the necessary skills and knowledge. Company participation and cooperation in the training programs is important to ensure the training content is updated and keep up with the trend of current market need. Apart from this, some of the technical and vocational schools can be suggested to incorporate the teaching with constructionrelated trades. This will create more exposure to the locals and tap the talents concurrently.

Although IBS would require higher cost, the innovation can help to save the labor cost in the long run. It is advisable to those with non-IBS technology to take up this technology to grow. Government authorities, like CIDB, also has to take some initiatives to encourage more contractors to take up this innovation. For instance, CIDB can offer some subsidy to those contractors.

Apart from the above, the incentives scheme can be introduced to the contractors to encourage and motivate them to adopt the IBS innovation. The innovation would require a higher cost of investment. The import taxes which levied on heavy machinery and equipment can be reduced so that it can help alleviate the burden of the contractors. At the same time, financial assistance can be offered to those contractors who have monetary difficulties.

\section{Research limitations and Suggestion}

There are some ideas that can be suggested for future study. Firstly, this study is restricted to Malaysia. Therefore, the implication of IBS innovation is not strong enough to be proven as a method to reduce labor demand. The IBS implementation is a potential area to be tested and discovered in other countries to confirm the result. Besides, a short period of data is also could be one of the research limitations. This research only checks on the requirement in 2016. There could be other variations affect the outcome. Hence, a longer period of data would further justify the effect of its implementation in the construction industry.

\section{CONCLUSION}

The acceptance rate of the IBS technology in the local construction industry is still relatively low in comparison to the developed countries, i.e., adoption in the country stands at around $30 \%$ to $35 \%$ and is expected to achieve a $50 \%$ rate in 2018 . To increase IBS usage, some of the factors that require more public education are the lack of economies of scale, an absence of an IBS construction ecosystem and negative public perception towards IBS-built homes (Oliewy et al., 2009).

One of the barriers to the acceptance of new technology is lack of knowledge, shortage of skilled worker and involvement from the local youth. High investment cost also puts the contractors on a halt to take up the innovations. Similarly, economic uncertainties also make 
contractors hesitant towards new innovation changes. These reasonings are consistent with the results found which suggest that IBS would require higher cost. It is true that IBS can help to reduce reliance on foreign labor. However, IBS seems to hire more foreign unskilled labor currently to avoid the project delay. In the long run, it is expected to pull more local skilled workers to work in the industry, but this could take a few years to transform and breakeven.

\section{ACKNOWLEDGEMENTS}

I would like to thank the Department of Construction Industry Development Board of Malaysia (CIDB) for the data access being granted. The survey data was undertaken by the CIDB, and their input is gratefully acknowledged.

\section{REFERENCES}

Adikaram, K. et al. (2014) 'Outlier detection method in linear regression based on sum of arithmetic progression', The Scientific World Journal. Hindawi, 2014.

Alinaitwe, H. M., Mwakali, J. and Hansson, B. (2006) 'Assessing the degree of industrialisation in construction-a case of Uganda', Journal of Civil Engineering and Management. Taylor \& Francis, 12(3), pp. 221-229.

Arif, F., Lodi, S. H. and Azhar, N. (2015) 'Factors influencing accuracy of construction project cost estimates in Pakistan: Perception and reality', International Journal of Construction Management. Taylor \& Francis, 15(1), pp. 59-70.

Bakker, M. and Wicherts, J. M. (2014) 'Outlier removal, sum scores, and the inflation of the type I error rate in independent samples $\mathrm{t}$ tests: The power of alternatives and recommendations.', Psychological methods. American Psychological Association, 19(3), p. 409.

Barnett, V., Lewis, T. and Pincus, R. (1995) 'Outliers in Statistical Data. 3rd edition. J. Wiley \& Sons 1994, XVII. 582 pp., £49.95', Biometrical Journal, 37(2), p. 256. doi: 10.1002/bimj.4710370219.

Beckman, R. J. and Cook, R. D. (1983) 'Outlier ... ....... s', Technometrics. Taylor \& Francis, 25(2), pp. 119-149. doi: 10.1080/00401706.1983.10487840.

Berkane, M. and Bentler, P. M. (1988) 'Estimation of Contamination Parameters and Identification of Outliers in Multivariate Data', Sociological Methods $\mathcal{E}$ Research, 17(1), pp. 55-64. doi: $10.1177 / 0049124188017001003$.

Cheema, J. R. (2014) 'Some general guidelines for choosing missing data handling methods in educational research', Journal of Modern Applied Statistical Methods, 13(2), p. 3.

Cook, R. D. (1986) 'Assessment of Local Influence (with Discussion)', Journal of the Royal Statistical Society B, 48(2), pp. 133-169. Available at: http://links.jstor.org/sici?sici=00359246\%281986\%2948\%3A2\%3C133\%3AAOLI\%3E2.0.CO\%3B2-E.

Devi, S. and Kalia, D. A. (2015) 'Study of data cleaning \& comparison of data cleaning tools', International Journal of Computer Science and Mobile Computing, 4(3), pp. 360-370.

EPU, E. P. U. (2015) 'The 11th Malaysia plan (2016-2020)', in Percetakan Nasional Malaysia Berhad, Kuala Lumpur, 2015.

Ertugrul, I. et al. (2016) 'Efficiency analysis of non-life insurance companies in terms of underwriting process with data envelopment analysis', European Scientific Journal, ESJ, 12(10).

Gnanadesikan, R. (2011) Methods for statistical data analysis of multivariate observations. John Wiley \& Sons.

Greene, W. H. (2003) Econometric analysis. Pearson Education India.

Hamid, A. R. A., Singh, B. and Mazlan, M. S. (2013) 'The construction labour shortage in Johor Bahru, Malaysia', International Journal of research in engineering and technology, 2(10), pp. 508-512. 
Hanrui, B. A. O. and Xun, A. N. (2011) 'Reliability test on oil field efficiency with DEA', Energy Procedia. Elsevier, 5, pp. 1473-1477.

Jarkas, A. M. and Bitar, C. G. (2011) 'Factors affecting construction labor productivity in Kuwait', Journal of construction engineering and management. American Society of Civil Engineers, 138(7), pp. 811-820.

Jarkas, A. M. and Younes, J. H. (2014) ‘Principle factors contributing to construction delays in the State of Qatar', International Journal of Construction Project Management. Nova Science Publishers, Inc., 6(1), p. 39.

Jarrell, M. G. (1991) ‘Multivariate Outliers. Review of the Literature.' ERIC.

Kang, H. (2013) 'The prevention and handling of the missing data', Korean journal of anesthesiology, 64(5), pp. 402-406.

Liao, H., Li, Y. and Brooks, G. (2016) 'Outlier impact and accommodation methods: Multiple comparisons of Type I error rates', Journal of Modern Applied Statistical Methods, 15(1), p. 23.

Molinari, F. (2010) 'Missing treatments', Journal of Business \& Economic Statistics. Taylor \& Francis, 28(1), pp. 82-95.

Navamukundan, A. (2002) 'Labour Migration in Malaysia-trade union views', Migrant Workers Labour Education, 4(129), pp. 110-115.

Oliewy, M. Q., Mustapha, K. N. and Mohammad, B. S. (2009) 'Advantages of industrialized building system in Malaysia', in proceedings of Student Conference on Research and Development (SCOReD).Malaysia.

Patel, S. (2012) 'Requirement to cleanse DATA in ETL process and Why is data cleansing in Business Application?', International Journal of Engineering Research and Applications (IJERA), 2(3), pp. 840842.

Qin, B. et al. (2009) 'A rule-based classification algorithm for uncertain data', in Data Engineering, 2009. ICDE'09. IEEE 25th International Conference on. IEEE, pp. 1633-1640.

Rousseeuw, P. J. and Van Zomeren, B. C. (1990) 'Unmasking multivariate outliers and leverage points', Journal of the American Statistical association. Taylor \& Francis, 85(411), pp. 633-639.

Zaki, S., Mohamed, S. and Yusof, Z. (2012) 'Construction skilled labour shortage-the challenges in malaysian construction sector', International Journal of Sustainable Development, 4(5), pp. 99-108.

--0--

DOI: https://doi.org/10.18034/ei.v6i2.227

Online Archive Link: https://abc.us.org/ojs/index.php/ei/issue/archive 